Boise State University ScholarWorks

9-1-2004

\title{
Why Aristotle Says There is No Time Without Change
}

Tony Roark

Boise State University 


\title{
Why Aristotle Says There Is No Time Without Change
}

\author{
Tony Roark
}

The title of this paper is intended as a provocative (but friendly) reference to Ursula Coope's recent article 'Why Does Aristotle Say That There Is No Time Without Change?', which provides much of the impetus for the present paper. ${ }^{1}$ For although Coope's strategy in answering this question is admirable, and although I think that her criticisms of the standard interpretation of the argument that opens Physics IV 11 hit their mark, I believe that her own interpretation fails and that something rather like the standard interpretation is correct. In the first section, I rehearse Coope's treatment of the standard interpretation and critically evaluate her alternative to it. In the second section, I present an interpretation of the argument that seems to me to succeed where the others fail and also to hold the promise of being quite fruitful in reconstructing the rest of Aristotle's temporal theory. While such a reconstruction lies well beyond the scope of this paper, I shall conclude by mentioning a few of the more significant points that fall out of the interpretation developed here.

\section{Fleshing Out the Argument: Two Schools}

Aristotle's constructive account of time begins in Physics IV 11, which opens with a hotchpotch of arguments whose relation to one another is not immediately evident. His first move is to qualify two arguments in

1 Ursula Coope, 'Why Does Aristotle Say That There Is No Time Without Change?', Proceedings of the Aristotelian Society 101 (2001) 359-67

APEIRON a journal for ancient philosophy and science 0003-6390/2004/3703 227-246 \$16.50 CAcademic Printing \& Publishing 
IV 10 against identifying time with change by conceding that time does not exist without change (Alla mēn oud' aneu ge metaboles, 218b21). He then offers what appears to be an argument for the concession and then restates the conclusion at $218 \mathrm{~b} 33$. The sole premise offered in support of the conclusion, so it seems, is the observation that we perceive time whenever we perceive change, but never when we don't perceive change. ${ }^{2}$ Tidied up a bit, this argument runs as follows:

Argument A (218b21-19a1)

1. We perceive time when, but only when, we perceive change.

2. Therefore, time does not exist without change.

Aristotle announces that we must take this conclusion as the starting point and that our task is to determine precisely what time has to do with motion and change (219a2-3), strongly suggesting that he imagines that the argument is more or less complete as stated.

What are we to make of Argument $A$ ? Why should we regard it as valid (if indeed it is intended to be deductive)? Unfortunately, Aristotle is of little help; rather than explaining how he intends the argument to work, he simply offers anecdotal evidence for the truth of the premise. In support of the claim that perceiving change is a necessary condition for perceiving time (one half of the premise, construed as a biconditional) ${ }_{1}^{3}$ he recounts a legend according to which sick individuals would go to Sardinia for treatment followed by a five-day period of sleep. ${ }^{4}$ Because they do not notice anything going on around them while they are asleep (and, presumably, because they emerge from their long slumber disoriented, perhaps unaware even that they have been sleeping), it doesn't occur to them that any time has passed without their notice (ou dokei ... gegonenai chronos, 218b21-7). The sleepers 'connect up the former now with the later now and make them one, removing what's between for failing to perceive it' (218b25-7). So noticing change seems to be necessary for noticing the passage of time.

2 Despite Aristotle's diverse terminology (metabole, kinēsis, phora), I shall follow Coope's lead in speaking primarily of change.

3 I shall throughout this paper ignore certain technicalities by referring to this claim as a biconditional and to its parts as conditionals.

4 Cf. W.D. Ross, Aristotle's Physics (Oxford: Clarendon 1936), 597. 
Strangely enough, Aristotle does not offer any justification for the other half of Argument $A^{\prime}$ 's premise until after he has restated the argument's conclusion. This, as we shall see, is just one way in which the argumentative structure of the opening passages of IV 11 is a muddle. At any rate, the drowsy imagery of Aristotle's first illustration carries over into the second, which is supposed to convince us that perceiving change is sufficient for perceiving time:

[F]or even if it is dark and we are not subject to bodily sensations, but some sort of change occurs in the soul, it immediately seems that some time has also passed. (219a4-6)

While one might question whether these illustrations really do establish the truth of the premise of Argument $A$, the claim is plausible enough. Granted, we typically do not consciously entertain the proposition that time is passing whenever we attend to some particular change, but we certainly are disposed to say that time passes whenever we witness change, and no sane person (or so one might think) would ever claim that change can take place outside of time. ${ }^{5}$

But even if we are willing to grant the truth of its premise, the logical character of Argument $A$ is questionable, to say the least. Surely there must be some logically adequate suppressed premise that would be acceptable to Aristotle. But what is it? Two schools of thought have emerged under the influence of this problem.

The traditional school of thought is one I shall call the 'verificationist school', and includes the likes of Sydney Shoemaker, Richard Sorabji, and Edward Hussey. ${ }^{6}$ According to the verificationists, Aristotle is committed to the following suppressed premise: any postulation of imperceptible temporal intervals is false (or perhaps even meaningless). ${ }^{7}$ If we construe the premise of Argument $A$ so as to imply the claim that any

5 The parenthetical hedge makes room for Aristotle's own view on the matter. He maintains in $\mathrm{Ph}$ IV 14 that change would exist without time, were there no counting souls (223a21-9). I shall say more on this below.

6 Sydney Shoemaker, 'Time Without Change', Journal of Philosophy 66 (1969) 363-81; Richard Sorabji, Time, Creation, and the Continuum (Ithaca, NY: Cornell University Press 1983); Edward Hussey, Aristotle's Physics, Books III and IV (Oxford: Clarendon Press 1983)

7 Cf. Sorabji, 75. 
temporal interval free of change (such as there might be) would be imperceptible, then the supplied verificationist premise licenses the conclusion that there simply aren't any such changeless intervals. Time does not exist without change.

Coope's principal objection to this interpretation is that it renders half of the premise of Argument $A$ superfluous. The supplied verificationist premise needs just the claim that we perceive time only when we perceive change to justify the conclusion; why, then, would Aristotle bother claiming that we perceive time whenever we perceive change? The claim of sufficiency could more easily be written off as a simple infelicity were it not for the fact that Aristotle repeats the biconditional after restating the conclusion of Argument $A$ (219a3-4). The verificationist therefore seems committed to the view that Aristotle either fails to perceive the superfluous nature of the sufficiency claim, or he simply neglects to point out that it is superfluous. Coope rightly maintains (360-1) that this is an undesirable commitment, and that an otherwise equally plausible alternative interpretation that accounted for both halves of the biconditional would be far preferable.

An additional objection to the verificationist reading points up the peculiarity of attributing the suppressed verificationist premise to Aristotle in the first place. Why should we take Aristotle to have verificationist leanings in connection with time when he seems to have them nowhere else? In the absence of some independent reason to attribute such a view to Aristotle (and the verificationists provide none) ${ }_{1}^{8}$ the move looks ad hoc.

The alternative interpretation that Coope recommends seeks to evade both of these objections and serves as the touchstone for the other school of thought, which I shall call the 'Owenian school'. Coope takes Aristotle's argument at the opening of IV 11 to employ a method he employs elsewhere, namely that of arguing from appearances. As Owen notes in his famous essay, ${ }^{9}$ Aristotle treats 'phainomenon' as an open-textured

8 Strictly speaking, this isn't true, since Hussey looks to IV 14 for support for his supplemental verificationist premise (142). Coope objects (361) that this couldn't be right insofar as the discussion in Chapter 14 presupposes Aristotle's official definition of time, and the definition presupposes the soundness of Argument A. I concur.

9 G.E.L. Owen, 'Tithenai ta Phainomena', in Aristote et les Problemes de Méthode, ed. S. Mansion (Louvain: Publications Universitaires de Louvain 1961) 
term, so that arguing from appearances might involve reasoning from empirical observations, reckoning what the majority of people believe, or considering the accepted usage of an important term. Coope has something like the second sense in mind: 'On [Aristotle's] view, the fact that we make this assumption [sc., that there is no time without change] in our ordinary judgements provides a prima facie ground for taking it to be true' (362). The locus classicus for Aristotle's commitment to the principle invoked here is Nicomachean Ethics X 2:

Those who object that that at which all things aim is not necessarily good are talking nonsense (mêe outhen legousin). For we say that that which everyone thinks really is so (pasi dokei, taut' einai); and the man who attacks this belief will hardly have anything more credible to maintain instead. (1172b36-3a2)

The principle Aristotle employs in this passage is rather stronger than the one invoked by Coope, as Aristotle indicates that contradicting common opinion amounts to talking nonsense, whereas Coope's interpretation requires only that doing so is prima facie mistaken. But so much the better for Coope's purposes! As she reads Physics IV 11, Aristotle's commitment to this principle figures in his larger program in the following way: (a) Aristotle wants 'to set up a starting point for his inquiry into time ... by assuming that time is essentially related to change' (362); (b) he attempts to justify this starting point by making plausible the claim that time cannot exist without change and also the claim that change cannot exist without time (362-3); (c) the explicit reason provided for these claims is the observation that we perceive time when, but only when, we perceive change (ibid.); (d) the judgments attending these noticings 'embody' the assumptions that time cannot exist without change and vice versa (ibid.); (e) by employing the principle in question, the alleged fact appealed to in (d) effectively satisfies the desideratum specified in (b), and therefore serves to set up the intended starting point identified in (a).

It is item (b) that helps the Owenian school evade the first objection to the verificationist interpretation. By insisting that Aristotle is arguing tacitly for the converse of the explicitly-stated conclusion that there is no time without change, Coope manages to bring the sufficiency claim of Argument $A$ 's premise into the picture. Her reasons for attributing the additional conclusion to Aristotle is that it is needed for assuming that time is essentially related to change' and that parity of reasoning seems to commit him to it (362-3). 
The Owenian school evades the second flaw in the verificationist interpretation by employing 'a principle that is already familiar from elsewhere in Aristotle's work' (365), rather than one that looks tailormade for the problematic passage. It seems that Coope is on firmer ground here, appealing as she does to a well-established tradition concerning one of Aristotle's dialectical methods.

Now, with respect to the first point, I find Coope's case to be wanting. Why, we should ask, doesn't Aristotle make explicit the claim that change cannot exist without time, if he were in fact committed to it? Coope's explanation (in a footnote) is this:

Perhaps it is because he wants to draw the former conclusion [sc., that time is essentially related to change] rather than the latter [sc., that change is essentially related to time] that he places so much more emphasis on the claim that there is no time without change than on the claim that there is no change without time. $(363, \mathrm{n} .13)^{10}$

It is surely an understatement to say that Aristotle places 'more emphasis' on the claim that there is no time without change, since he nowhere says that there is no change without time. Indeed, he explicitly denies the claim that it is impossible for change to exist without time in IV $14 .^{11}$ Had Aristotle admitted even provisionally that there is no change without time, one would have expected him to make some kind of remark about abandoning the idea when he contradicts it in the final chapter of Book IV, but he makes no such remark. This element of the Owenian school's interpretation strains the text to its very limits.

With respect to the second point, I do not deny that Aristotle argues from appearances elsewhere in the Physics. However, it does not seem to me that Aristotle is arguing from appearances at the opening of IV 11. To see why, we shall need to examine Coope's specification of how the Owenian principle is employed in this context:

[Aristotle's] view, I believe, is that our practices in judging whether or not time has passed embody certain assumptions about the relationship

10 I am grateful to Marc Cohen for helping me see that Coope seems to use the phrase 'is essentially related to' as a variant on 'is defined in terms of'.

11 Coope notes this fact herself in connection with her discussion of Hussey's version of the verificationist reading (cf. n. 8 above). 
between time and change. In making these judgements we take it for granted that there is no time without change .... (362, emphasis added)

Coope goes on to quote two familiar pieces of the text relevant to her interpretation and then reiterates her position:

Whenever it seems that a certain time has passed, a certain change seems to have passed together with it (219a7-8).

When we do not mark any change but the soul seems to remain in one indivisible, it follows that we think there is no time (218b29-32).

Aristotle thinks that when we make these ordinary judgements about whether time has passed, we are assuming that there is no time without change. (362, emphasis added)

Notice that the judgments behind which the alleged embodied belief lies are specified narrowly as ones concerning the passage of time. So one's judgment that a certain interval of time has passed allegedly embodies the belief that there is no time without change. In the passages Coope cites, Aristotle is expressing the necessity of perceptions of change for the perception of time and, equivalently, the sufficiency of perceptions of time for the perception of change. How is this interpretation supposed to work?

In order to answer this question it is first necessary for us to understand what Coope has in mind when she talks about embodied beliefs:

I have spoken of beliefs that "lie behind" or are "embodied in" the judgements we make. But what is it for a belief to be "embodied in" the judgements we make? Aristotle is not claiming that we all explicitly believe that there is no time without change or change without time. His claim is only that these beliefs would explain and justify the particular judgements we make about whether or not time has passed. $(365$, n. 16)

The belief that there is no time without change, then, is supposed to be capable of explaining and justifying one's judgment that some interval of time has passed. But this hardly could be correct. The embodied belief is rather better suited to explain and justify the judgment about the occurrence of change: if an agent judged that some interval of time had transpired, then a dispositional belief that time requires change might well lead him to believe that some change had also occurred. This way 
of thinking about the matter certainly accords much better with the text that Coope cites, since it takes perceptions of time to be sufficient for perceptions of change. An analogous problem plagues Coope's treatment of the putatively embodied belief that change requires time, as she maintains that this belief lies behind our judgments concerning the occurrence of change. ${ }^{12}$

This flaw could be remedied simply enough by systematically interchanging the two types of embodied belief. Unfortunately, there are other problems for this interpretation. For first of all, I think it's quite implausible to maintain that either our judgments about change or those about time are acquired or justified inferentially, and I also think that Aristotle would have recognized the implausibility. Our beliefs about both change and time arise out of experience and are justified (when they are) by the same. ${ }^{13}$ But even setting that worry aside, when conjoined with her account of the role played by embodied beliefs, Coope's commitment to the claim that Aristotle argues from appearances to the conclusion that time requires change and the conclusion that change requires time saddles Aristotle with absurdity. Recall: the belief that time requires change is allegedly embodied in our judgments concerning the passage of time, and the belief that change requires time is allegedly embodied in our judgments concerning the occurrence of change. ${ }^{14}$ Embodied beliefs are ones that 'would explain and justify' these judgments. Not by themselves, of course: each must take an antecedent judgment concerning change or time to serve as an initial premise. That's the point, as I understand it, of saying that the conditionals Aristotle trots out reflect 'our ordinary thinking' (363). One perceives some change in

12 Although Coope does not explicitly specify the judgments as such, when one considers the context in which she mentions 'these ordinary judgements' (363), it's clear that she must mean judgments about change.

13 Cf. Cooper's complaint about the traditional interpretation of Aristotle's treatment of the practical syllogism in $E N$ and $M A$ : ' $[\mathrm{H}]$ aving decided to eat chicken, the agent approaches the table, sees the chicken and takes some - the act of perception not providing a piece of information which is then, as it were, detached and used in a little argument issuing in the act of eating, but instead itself forming a link in a psychological chain leading from decision through perception to action.' (John M. Cooper, Reason and Human Good in Aristotle [Indianapolis: Hackett 1986], 52)

14 For simplicity's sake I here retain Coope's pairings of embodied beliefs with associated judgments. 
his soul; he then determines that some interval of time must have passed on the basis of his implicit belief that change requires time.

The problem, to put it bluntly, is that the explanatory scheme Coope sketches forms a closed figure. For unless our judgments concerning the passage of time are inexplicable, there is some explanation for them. If the embodied belief is not wholly irrelevant to the actual explanation for these judgments, then if the embodied belief would explain the judgments about time, it does explain them. ${ }^{15}$ That is, to make the embodied belief actually relevant, it must be made to be an element in the explanatory chain for the explicit judgment. So part of the explanation for one's believing that time has passed is his implicit belief that change requires time. ${ }^{16}$ But that's not the complete explanation. Another part of the explanation is his having perceived some episode of change. So if the embodied belief is at all relevant to the judgment in question, then the judgment is formed (in part) on the basis of another judgment concerning the occurrence of change. As I indicated above, this explanation strikes me as specious; but because Coope also maintains that the explanation for one's believing that change has transpired is formed (in part) on the basis of another judgment concerning the passage of time, the explanatory trail loops back on itself: we believe that time has lapsed in part because we believe that change has occurred, and we believe that change has occurred in part because we believe that time has lapsed. Since circular explanations aren't genuine explanations at all, Coope is mistaken when she claims that the two allegedly embodied beliefs would explain our judgments concerning time and change. ${ }^{17}$

15 As Coope herself remarks in the footnote excerpted above, '[Aristotle] is saying, rather, that this is a belief which explains and justifies our judgements' $(365, n$. 16, emphasis added). She refers here to Aristotle's account of voluntary actions in EN III 5 , but if the reference is intended to illuminate her application of the Owenian principle to the argument in $P h$ IV 11, the subjunctive formulation used earlier is unnecessarily weak.

16 Here I employ the revised pairings of embodied beliefs and associated judgments, since I'm attempting to characterize the explanatory mechanism charitably.

17 Similar problems arise in connection with Coope's claim regarding justification, though matters get more complicated here on account of the controversy surrounding the nature of justification itself. I think the foregoing objection framed in terms of explanation casts sufficient doubt upon Coope's interpretation to motivate finding a better alternative, so I shall set aside this issue. 
My objection can be summed up quite simply. Coope's interpretation of Aristotle as arguing from appearances involves positing explanatory mechanisms. These mechanisms proceed from a belief about change (or time) and an ontological principle concerning the relation between change and time to a belief about time (or change). But because she thinks Aristotle is committed to symmetrical ontological principles, the perceptual beliefs in the explanatory scheme stand both as explanans and explanandum to each other. This is obviously unsatisfactory. By the principle of charity, then, we may conclude that Coope must be mistaken in one way or another: either Aristotle is not arguing from appearances at the opening of V 11, or else he is not committed to the claim that change cannot exist without time. I shall argue that she is mistaken on both counts.

\section{A New Old School}

Despite its inadequacies, there is something right about the verificationist interpretation, and the interpretation I shall endorse bears certain affinities with it. I begin by examining some of the text that surrounds Argument $A$. After stating the initial conclusion that time does not exist without change and reiterating the point that we perceive change and time together (219a3-4), Aristotle draws what seems to be a more specific conclusion than that of Argument $A$ :

Argument B (219a2-10)

1. Time is either identical to change or is some aspect of change.

2. Time and change are not identical. (cf. 218b18.)

3. Therefore, time is some aspect of change.

Aristotle makes the claim that functions as the first premise at 219a8: hōste ètoi kinèsis è tès kinèseōs ti estin ho chronos. The inferential particle (hōste) suggests that this is a consequence of some earlier claim, but Aristotle has added nothing to the mix prior to making this assertion; he has simply reminded us that time and change are perceptually concomitant and rehearsed his second illustration in support of the premise of Argument $A$. So on what grounds does Aristotle make the claim?

I maintain that Argument $B$ is in fact part of Argument $A$, though Aristotle gives us precious little assistance in recognizing that this is the case. I read the inferential particle as indicating that the first premise of 
Argument $B$ is intended somehow to follow from the premise of Argument $A$. For consider just the form of Argument $A$ :

1. We perceive $x$ when, and only when, we perceive $y$.

2. Therefore, $x$ does not exist without $y$.

If Argument $B$ could be fashioned into the additional premises that are required for Argument $A$ 's cogency, two problems would thereby be solved: the otherwise lame Argument $A$ would be made fit, and the apparently spurious 'hoste' would find a home. In order to determine how Argument $B$ supplies the required premises for Argument $A$, we must address the following question: what relations between the values for $x$ and $y$ in the argument-form above could explain the truth of instances of the premise and simultaneously license the corresponding conclusion?

One relation that does the job is identity. If the substituends for $x$ and $y$ are coreferring terms, then (provided that 'perceives' is read de re) ${ }^{18}$ the instantiated premise of our argument-form will be true, and we have before us a very good explanation of its truth. If Phosphorus just is

18 The distinction between de re and de dicto perception is not to be confused with the distinction Aristotle draws in de An II 6 between kata sumbebēkos and kath hauto perception. Whereas the latter distinction is based upon the features of perceptible objects that are causally efficacious relative to the function of our various perceptual faculties, the former distinction trades on the difference between cause and content. For example, color (one of the 'proper perceptibles') and movement (a 'common perceptible') are perceived kath hauto, since our eyes are sensitive to these very things. In contrast, the son of Diares is perceived kata sumbebékos, since none of our perceptual faculties is attuned specifically to substances, let alone to male offspring of this particular man; what one perceives kath hauto is (say) a moving white thing that just happens to be the son of Diares. The distinction between de re and de dicto perception, as I conceive it, is glimpsed by Aristotle at Sens 446b18-24 and cuts across the distinction drawn in de An II 6. Something (which may, but needn't be a substance) is perceived de re just in case it originates a causal chain that produces a perceptual event in an agent. The agent might be wholly ignorant of the item's character and might even fail to recognize it altogether. The only requirement is that there is in fact something such that it contributes causally (in the typical sort of way) to an act of perception. On the other hand, de dicto perception consists in the conceptual content of an act of perception under which the agent perceives the intended item. So one might perceive the son of Diares variously as a moving white thing, as a man, or as the very man that he is. What one perceives de dicto is a moving white thing, a man, and the son of Diares, respectively. 
Hesperus, then it's obvious both that and why Theophanis perceives (de re) Phosphorus exactly when he perceives Hesperus, since there is but one object to be perceived. Additionally, it is also true that Phosphorus does not exist without Hesperus, since each of them is just Venus, and nothing can exist without itself. Hence, if the substituend-pair for $x$ and $y$ is a member of a set of pairs of coextensive terms, we have a viable reconstruction of Argument $A$.

Although identity renders the argument viable, it cannot be the justification that Aristotle has in mind, because he takes himself to have established in IV 10 that time is not identical with change (witness the second premise of Argument $B$ ). Therefore, we must look elsewhere. ${ }^{19}$

The alternative Aristotle considers in the first premise of Argument $B$ - sc., that time is some feature or aspect of change (tês kinēseōs ti) would certainly go a long way towards explaining the fact that we perceive time only when we perceive change, since perceiving the features of something plausibly requires perceiving (once again, de re) the thing itself. ${ }^{20}$ But surely there are values for $x$ and $y$, where $x$ is some feature of $y$, and yet it's false that we perceive $x$ whenever we perceive $y$. For example, if $x$ is the molar weight of some chemical compound $y$, there is nothing to guarantee that perceiving the latter strictly requires perceiving the former, in the de re sense of 'perceiving' or any other sense. Indeed, it would be wildly implausible to maintain that anyone ever perceives the molar weight of a particular chemical compound outside the rather extraordinary circumstances presented by laboratory experiments. ${ }^{21}$ Some features of perceptible objects are such as to be hidden in most contexts.

The very fact that there are such 'occult' features invites us to consider whether there might be some that are unmistakable, impossible to

19 Aristotle's claim regarding the possibility of change without time in Chapter 14 might thought to be additional grounds for rejecting identity, but see $n .8$ above.

20 This claim presumes that the feature in question belongs exclusively to the relevant token or type of perceptible item. For example, it's impossible that someone should perceive Callias' tallness without perceiving Callias himself. But more on this below.

21 I assume here that the molar weight of a chemical compound plays no significant role in determining the substance's perceptible features. If this assumption is incorrect (as it might be, for all I know), then by my own account of de re perception, one could perceive its molar weight de re. Such worries aside, I hope that my point is clear enough. Thanks to Jim Hankinson for making me aware of this concern. 
overlook. It seems to me that there are in fact such evident features of perceptible objects and that Aristotle might have just these in mind in his discussion of time, even if he failed to articulate the idea clearly in the context of that discussion. So let $m e$ be a bit more precise by giving a provisional definition of this notion:

(EF) For any pair of perceptibles $\langle x, y\rangle, x$ is an evident feature of $y$ iff $x$ is a feature of $y$, and for any percipient $z, z$ cannot perceive (de dicto) $y$ without also perceiving its $x$.

The idea here is that there are certain features of some items which are such that, should one fail to be aware of those features, one wouldn't be aware of the item itself. An example is the pair <volume, stone $>$ (where by 'volume' I do not mean any determinate quantity of volume, but simply some volume or other). If Theophanis fails to perceive a particular stone as having volume, it is very difficult indeed to fathom how he could possibly be aware of the stone at all. He could not be aware of the stone as a stone, at any rate, since perceiving some $F$-type thing as an $F$ plausibly requires the employment of the concept of $F$-ness, and any concept of a volumeless object is not the concept of a stone. ${ }^{22}$ Of course, the stone isn't identical with its volume, since it has other essential features (its mass, for example). Another example: <life, animal>. If Theophanis fails to perceive a certain animal as being alive, then he must not perceive the animal as an animal, since the concept of an animal (on Aristotle's view, at any rate - cf. de Anima 412b18-29) is in part the concept of a living thing.

These two examples illustrate the significance of giving 'perceives' a de dicto reading, for it's quite possible that an individual should perceive a stone as something other than a stone without perceiving it as something that has volume. (Perhaps he believes that what he sees is a reflected image in a mirror.) My present strategy is to exploit this fact by arguing that Aristotle takes the pair <time, change> to stand in the

22 Note that I am not making the implausible claim that in order to perceive a stone as such, one must have an apperceptive belief, part of the content of which being a representation of his concept of volume. That is, one needn't think about his concept of volume in order to perceive the stone as something possessing volume. All that is required is that his concept plays a role in his perceptual belief that a stone lies before him. 
evident feature relation, since his doing so would justify the problematic half of the premise of Argument $A$ : if time is an evident feature of change, then one would in fact perceive time whenever he perceived change.

Unfortunately, though, the (EF) relation does not obviously justify the claim that we perceive time only when we perceive change. The problem is that the definition places no exclusivity constraints on the relevant type of feature vis-à-vis its possessor. That is, while any given stone possesses a certain volume, so do elephants and eyeglasses. So while it may well be true that one must perceive volume whenever he perceives a stone as such, he will also perceive volume when he perceives an elephant as such, and it is therefore false that he will perceive volume only when he perceives a stone.

The solution to this problem is twofold. Greater care should be exercised in distinguishing types and tokens, and some kind of constraint must be imposed on the relevant types involved. I have been less than cautious in constructing my examples, since the pairs figuring in them are framed in heterogeneous terms. While 'volume' and 'life' are very commonly used as type terms or mass-nouns (one has no hesitation to use either term without any determiner), 'stone' and 'animal' are both more clearly token terms or count-nouns (one speaks indeterminately of stone and animal only in rather special circumstances). I hope that my laxity will be forgiven, however, in light of the fact that Aristotle is rather less careful than he ought to be in his own discussion of change and time. The premise of Argument $A$ (as well as its conclusion) treats 'time' and 'change' as type terms, ${ }^{23}$ while the illustrations offered as evidence for the premise are framed in terms of token episodes of change and intervals of time. The shift is unobjectionable so long as one makes certain assumptions about uniformity among members of the type and the representativity of the chosen examples. Aristotle apparently makes such assumptions.

When the $(\mathrm{EF})$ relation is recast to address these concerns, the resulting notion is that of an evident proper feature:

(EPF) For any pair of type-perceptibles $\langle\Phi, \psi\rangle, \Phi$ is an evident proper feature of $\psi$ iff every token of $\psi$ (and nothing else, except by

23 The lack of an indefinite article in Attic Greek lends to the confusion, but the absence of ' $t$ is' or some other determiner clearly indicates that Aristotle intends to be talking about time and change in general. 
virtue its relation to some such token) has some token of $\Phi$ as one of its features, and for any percipient $z, z$ cannot perceive any token of $\psi$ as a $\psi$ without also perceiving its token $\Phi$.

If the foregoing definition be thought too contrived to be found anywhere in Aristotle, one need only examine his discussion of properties in Topics V 1-3 to see that he practically illustrates it himself. Consider what he says at 131b33-6:

Thus, for example, a man who has stated that it is a property of a surface to be the primary thing that is colored, has used [in rendering the property] in addition something perceptible, being colored, but something which evidently always belongs (toiouto $d^{\prime}$ phaneron estin huparchon aei), and so the property of surface will in this respect have been correctly rendered.

Given my terminology, this passage indicates that Aristotle regards the pair <color, surface> as falling in the extension of the (EPF) relation. Color and surface are both types each of whose tokens are perceptible (they are type-perceptibles); every surface has some color or other as one of its features; ${ }^{24}$ if any non-surface has color, it has it by virtue of being related to a surface (they being the primary colored things); and anyone who perceives a surface as such cannot fail to perceive its color - the color is 'something which evidently always belongs' ${ }^{25}$ Other candidates from this section of the Topics: <rarity, fire>; <ensouled, living creature>; $<$ panmorphic, liquid $>$. In each case, an agent who fails to perceive the first member of the pair cannot properly be said to perceive the second

24 The surfaces of transparent substances (e.g., glass and water) might be thought to present a special challenge; however, Aristotle doesn't hesitate to commit himself to the claim that all bodies whatsoever are colored (Sens 437a6), and in fact it appears as though his theory of vision maintains that it is the surface of the air at the boundary of our eyes that is the immediate cause of our visual perception of bodies (cf. de An 419a11-b1, 423a21-b7, and Sens 439a17-30).

25 As a variety of the 'common perceptibles' (cf. n. 18 above), surfaces are perceptible by means other than sight, so it is not strictly correct to say that an agent cannot perceive a surface as such without perceiving it as colored. Perhaps Aristotle has in mind his view that sight is the most highly developed sense (cf. de An 429a3), under the influence of which one might well say that to perceive a surface in the fullest way possible, one must perceive it as being colored. 
member of the pair as such, because de dicto perception involves the employment of concepts, and in each case the first member of the pair is a perceptible feature, the concept of which is included in the concept of the second member. A more germane example is the pair <distance, space $>$, since Aristotle draws a tight connection between space, change, and time in Physics IV 11. ${ }^{26}$ This comparison cuts to the heart of Aristotle's temporal theory, and I shall touch on it briefly in the conclusion.

Like identity, the (EPF) relation gives us the means to account for the inference in Argument $A$. For if time is an evident proper feature of change, then we will perceive time only when we perceive change (it's a proper feature of change, after all), but also whenever we perceive change as such (since it's an evident feature). And so if Argument $B$ is taken as an argument for the claim that <time, change $>$ is included in the extension of the (EPF) relation, it can be incorporated into Argument $A$, and the resulting reconstruction is a rather plausible argument:

Argument A-cum-B

1. We perceive time when, and only when, we perceive change. (218b21-3, 219a3-8)

2. It follows abductively (hōste) from (1) that either (i) change and time are identical, or (ii) time is an evident proper feature of change, since no other explanation for the truth of (1) is available. (Cf. 219b8-9.)

3. But time and change aren't identical. (218b18)

4. Hence, time is an evident proper feature of change. (From 2, 3 - cf. 219b9-10.)

5. If $x$ is a proper feature of $y$, then $x$ does not exist without $y$. (Implicit premise)

6. Therefore, time does not exist without change. (From 4, $5-$ 218b21.)

26 'Since that which moves moves from something to something, and since every magnitude is continuous, motion follows magnitude; for it's because magnitude is continuous that motion is also continuous, and it's because motion is that time is' (Ph 219a10-14). Cf. Metaph 1021a29-32. 
I take the plausibility of this argument as a mark in favor of my interpretation. Another mark in its favor as compared to Coope's: my interpretation is much more comfortable with Aristotle's remarks that we perceive change and time together (hama - 219a3) and that we perceive time immediately (euthus - 219a6) when we perceive change, since I claim that they are related objects of a single act of perception, whereas Coope interposes an inference (albeit unconscious) between the perception of one and the judgment that the other must also be present. But though these features my interpretation are favorable, there are two significant objections that must be addressed before any general claim to its superiority may be made.

The first objection is that my interpretation imports far too much content into the argument, content that should have been made explicit were it intended. I respond, first, by pointing out that without the added content, the argument flounders, and as I have tried to show in section I, no other means of repairing the argument is satisfactory. Second, I should like to note that even having imported that content, the argument truly does represent just an opening move, since knowing only that time is an evident proper feature of change logically entails little more than the fact that time cannot exist without change. The important question still remains: in what way is time an evident proper feature of change? Aristotle's answer is that time is the number of change. The explication of this answer occupies Aristotle's efforts for the remaining chapters of Book IV. Compare this with the case of colors and surfaces: one might well be convinced that color is an evident proper feature of surface without having anything like a philosophically-respectable account of color. ${ }^{27}$ So I insist that although my interpretation does import a good deal of content into the argument, it does not import too much: the additional content is needed for the argument to go through, is not unfamiliar to Aristotle, and in no way threatens to render the rest of his discussion of time otiose.

The second objection takes the form of a tu quoque. I complained in section I about the adequacy of Coope's explanation for Aristotle's failure to draw explicitly the conclusion she attributes to him (sc., that

27 Note that although Aristotle seems to make color an evident perceptible feature of surface in Top V 3, he obviously does not think that his having done so relieves him of the burden of providing an account of color, since he undertakes the provision of just such an account in Sens 3. 
there is no change without time); what explanation can I give for the fact that Aristotle claims that there is no time without change, but doesn't claim that there is no change without time? The short answer is that Aristotle doesn't define change in terms of time. Fleshing out this response highlights a striking difference between my interpretation and that of the Owenian school.

Coope takes Aristotle in a way to be reasoning from common sense. On this reading, his project is philosophically naïve, since it proceeds by way of discovering certain assumptions that we all allegedly make, but about which we were previously unaware. I do not share Coope's assessment of this situation. I do not think that Aristotle's arguments are intended to help him discover what time is; I think he comes to the table with a fully developed view in hand and that his arguments are intended to convince the reader that his definition is correct. But if Aristotle's arguments are polemical rather than probative, what should prevent him from deploying other elements of his philosophical arsenal? Specifically, why shouldn't Aristotle exploit the sophisticated account of change and motion that he gives in the preceding book of the Physics?

I maintain that nothing should prevent him. Indeed, it seems obvious to me that he must have this account in mind if his definition of time is to avoid circularity. As Coope herself notes $(363, n .12)$, it is the fact that Aristotle defines change in terms of potentiality and actuality - rather than in terms of temporally-variant property instantiation - that permits him to define time noncircularly as 'a number of change with respect to the before and after'. I, too, have argued that despite appearances, the definition is not at all circular, since Aristotle's kinetic theory is developed in temporal-free terms and can be used to give a non-temporal sense to 'before' and 'after' as they appear in his definition of time. ${ }^{28}$

Aristotle unveils his definition of time very shortly after rehearsing the arguments that open IV 11, and yet he nowhere indicates that he is abandoning some other conception of change in favor of his own definition. We ought to conclude, then, that he has had it in mind all along. And if that is so, there is good reason for him to reject the idea that change could not exist without time, as time does not figure in the ti $\bar{e} n$ einai of change. But it still remains an open possibility that time is some proper feature or other of change, and thus could not exist in its absence. It is 
precisely this possibility that gets developed as Aristotle's considered view on time.

\section{Conclusion}

I claim that the interpretation I am advocating is superior both to the Owenian school's and the verificationists', even though my own interpretation logically entails the latter. On my reading of opening of IV 11, Aristotle takes time to be a rather specific kind of perceptible feature of change. According to the verificationists, Aristotle rejects the idea of imperceptible temporal intervals. But if my interpretation is correct, imperceptible temporal intervals would be imperceptible perceptible features, and these are obviously impossible. Thus, my interpretation entails the verificationists'. Still, my interpretation ought to be preferred over theirs insofar as it provides a substantive explanation for Aristotle's rejection of imperceptible temporal intervals and supports both halves of the biconditional in the first premise of Argument $A$, whereas the verificationists' does neither.

My interpretation is superior to that of the Owenian school insofar as it makes use of the sufficiency claim in the first premise (we perceive time whenever we perceive change) without attributing to Aristotle the claim that change cannot exist without time, a claim that he explicitly rejects in IV 14 and is unsupported by his own account of change. But aside from this fact, my interpretation doesn't saddle Aristotle with an implausible conception of the origins and justification of our beliefs about the passage of time and the occurrence of change, even while claiming that Aristotle is arguing from appearances. Coope's interpretative motives are commendable, but her treatment of the argument does not stand up to scrutiny.

I close with a brief remark about the possible fruit borne by my interpretation. I said in the previous section that there is reason to think that Aristotle would include <distance, space $>$ in the extension of (EPF) and that he draws a tight connection between space, change, and time immediately after giving Argument $B$. If we think about the matter as Aristotle does, it should be clear to us that distance, conceived as a metric, is in some sense a mind-dependent feature of space. Because space is infinitely divisible, there are no natural units of space. We adopt some conventional length, treating it as a standard, and our treatment of it as such involves regarding it as 'undivided in perception' (Metaphysics 1053a23). So without the activity of percipient agents like ourselves with 
certain intentions and interests, there would be no non-trivial answer to the question 'What is the distance between objects $a$ and $b$ ?' Thus, not only is distance an evident proper feature of space (something one cannot fail to perceive whenever he perceives a spatial interval as such), its very existence depends in part upon acts of perception.

But given the fact that Aristotle envisions change (rather, locomotion, the paradigmatic type of change, according to Physics 260a27-9) as being parasitic upon spatial intervals, he must imagine that there is some kinetic analogue to distance. That's just what time is: the metric of change (or as Aristotle puts it, 'a number of change (arithmos kineseōs)'). The analogy is not to be taken lightly. Aristotle's view, as I understand it, is that distance stands to space in precisely the same way that time stands to change. This explains both the abundance of perception-talk long after Arguments $A$ and $B$ have been set out and his remark about the possibility of change without time in IV $14 .{ }^{29}$

\author{
Department of Philosophy \\ Boise State University \\ 1910 University Drive \\ Boise, ID 83725-1550 \\ U.S.A. \\ troark@boisestate.edu
}

29 I wish to extend my sincere gratitude to Sylvia Berryman, S. Marc Cohen, Jim Hankinson, and David Sedley for their gracious comments on earlier drafts of this paper. 